\title{
EDITORIAL
}

\section{OPHTHALMIC EPIDEMIOLOGY AND DAME IDA MANN}

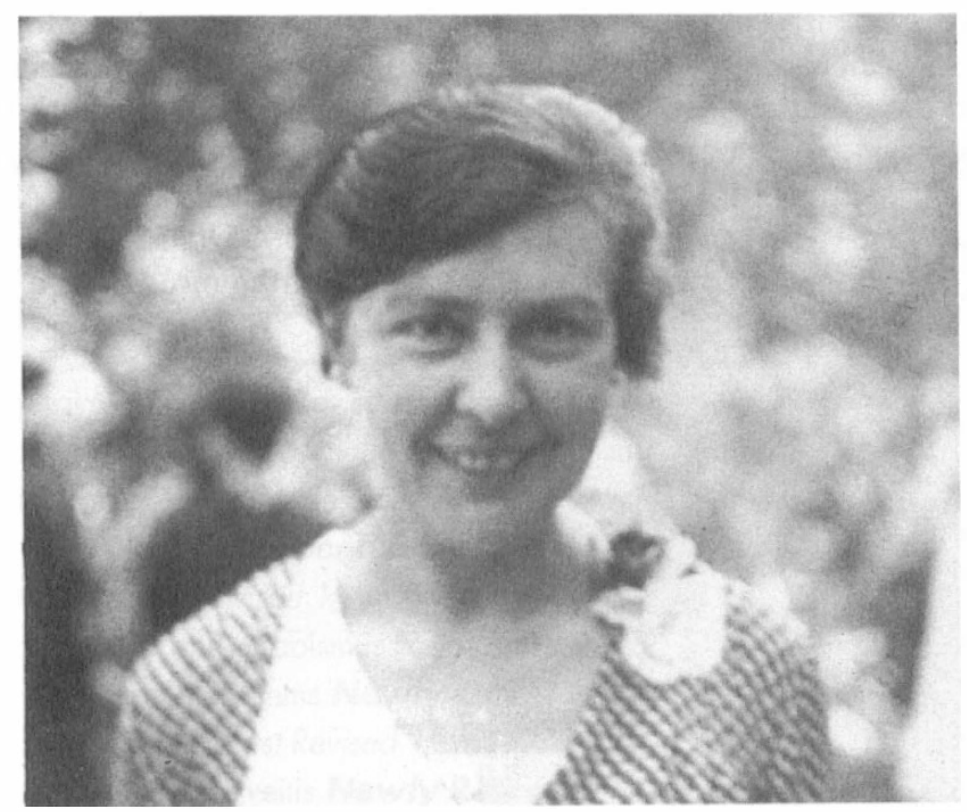

Ida Mann in 1939. (Courtesy of Dorothy Potter and Roger Buckley.)

It was Dame Ida Mann's work in the field which gave the subject to a symposium at the Oxford Ophthalmological Congress in 1993, entitled 'Epidemiology for the Clinical Ophthalmologist: A Tribute to Ida Mann'. It marked the centenary of the birth of one of the century's luminaries in ophthalmology.

Born in London, Ida Mann had an uncle farming wheat in Western Australia. The pieces were already in place for that astonishingly precise division of her life into an 'English period', as described by her academic descendent Professor A. J. Bron in his elegant obituary for the Archives of Ophthalmology in 1984, and an 'Australian period' which began only in her late fifties.

The 'English period' was awash with innovations. After qualifying in medicine, at a time when few women did, she blazed a trail for feminism. Her DSc from London University was published in 1928 as the first definitive book in this country on The Development of the Human Eye, and along with Congenital Defects of the Eye in 1937 became a standard text. After an appointment as Assistant Surgeon to the Central London Ophthalmic Hospital (later to become the Institute of Ophthalmology) she became the first female honorary consultant to the Royal London Ophthalmic Hospital - Moorfields. She was then chosen as the Margaret Ogilvie's Reader in Ophthalmology at Oxford, where thereafter a personal chair was created making her the first ever female professor of that university.

Her wide interests included comparative anatomy at London Zoo. She brought news of the Gullstrand slit lamp from Vogt to London. With Joseph Dallos, whom she persuaded to leave the beleaguered Budapest before the First World War, she established the first contact lens clinic in London. During the war she studied mustard gas keratitis, thyroid eye disease, mepacrine toxicity and was a guinea pig for Professor Florey and penicillin. Medal lectures abounded: the Doyne in 1928, the Harrison Gale in 1929, the Nettleship in 1932 and the Montgomery in 1935. 
It was the 'Australian period', during which she investigated the epidemiology of eye diseases among the Aborigines in the north-west of the continent, that prompted the Oxford Congress to dedicate a symposium to this subject. After the Second World War, disenchanted by the creation of the National Health Service, she went to Australia for the second time and stayed. Her frail husband, Professor William Gye, died shortly afterwards and an opportunity arose for the lady, now a significantly senior woman of 59, to embark on a huge adventure in the outback of Western Australia. She made a study of trachoma in particular, not only from the scientific point of view but also from the therapeutic and prophylactic standpoint. It was Ida Mann, with Dorothy Perret, who was largely responsible for isolating Chlamydia trachomatis in Australia.

Ida Mann won acclaim worldwide, but particularly in the south-west Pacific with work in Papua New Guinea. Out of this came her book entitled Culture, Race, Climate and Eye Disease in 1966.

The proceedings of the present symposium include a summary of epidemiological techniques and the problems of assessing the prevalence of eye disease in the community, the assessment of ophthalmic services and the philosophy behind the randomised controlled trial. A paper from the symposium on the epidemiology of microbial keratitis demonstrates how epidemiological techniques can be used to assess risk. The last paper in the symposium on geographical epidemiology has recently been published (Gatrell AC et al. The geographical epidemiology of ocular diseases: some principles and methods. Eye 1995;9:358-64). Together these give a view of the scope of epidemiology and its relevance to the practising ophthalmologist - a legacy from Ida Mann. 